\title{
Grammatical priming of inflected nouns
}

\author{
G. LUKATELA \\ University of Belgrade, Belgrade, Yugoslavia \\ A. KOSTIĆ \\ University of Connecticut, Storrs, Connecticut 06268, and \\ University of Belgrade, Belgrade, Yugoslavia \\ LAURIE B. FELDMAN \\ Haskins Laboratories, New Haven, Connecticut 06510 \\ and \\ M. T. TURVEY \\ University of Connecticut, Storrs, Connecticut 06268, and \\ Haskins Laboratories, New Haven, Connecticut 06510
}

\begin{abstract}
In normal linguistic usage, the inflected nouns of Serbo-Croatian are usually preceded by prepositions that help to specify which particular grammatical case is intended and to stress the noun's function in the sentence. In a lexical decision task, it was demonstrated that lexical decision times to nouns in a grammatical case that demands a preposition were faster when the preposition was appropriate to the case than when it was either inappropriate to the case or a nonsense syllable. This result lends support to the intuition that priming can occur among sentential components.
\end{abstract}

It is easily demonstrated that naming a word is facilitated by the prior occurrence of the word itself or a semantically related word (e.g., Fischler, 1977; Meyer, Schvaneveldt, \& Ruddy, 1975; Scarborough, Cortese, \& Scarborough, 1977), but it is debatable whether such facilitation occurs in normal linguistic usage. Semantic priming of lexical items is most commonly demonstrated in the context of word lists, and in the view of Forster (1976), it is a phenomenon that may well be restricted to this context. Forster sees related words as interconnected or cross-referenced in the lexicon, and this cross-referencing is the basis for semantic facilitation effects. Given this view, Forster (1976) is dubious that sentence fragments can provide the semantic context that primes lexical entries; rarely are individual words in sentences of English semantically related. Forster reports that words that were predictable from a sentence context were not named faster than words that were less predictable. But there are some strong hints to the contrary (e.g., Blank \& Foss, 1978; Morton \& Long, 1976; Schuberth \& Eimas, 1977; Stanovich \& West, 1981; Underwood, 1977).

A procedure that has proved extremely sensitive to short-term facilitatory, and inhibitory (see Neely, 1977), effects of one linguistic item on another is the lexical decision task. Quite simply, in this task, a subject is

This research was supported in part by NICHD Grant HD08495 to the University of Belgrade and in part by NICHD Grant HD-01994 to Haskins Laboratories. Reprint requests should be sent to $M$. T. Turvey. shown a string of letters and is required to respond as quickly as possible to its lexical status; that is, the subject decides whether the letter string is a word. The lexical decision task is used in the experiment reported here to look at the possibility of facilitating the processing of inflected nouns through the prior presentation of an appropriate preposition.

Inflection is the major grammatical device of SerboCroatian, Yugoslavia's principal language. A noun "system" in Serbo-Croatian consists of seven cases, both in the singular and in the plural. Excluding the nominative and vocative cases, each grammatical case has a number of possible meanings. The particular meaning is specified by a preposition and/or by the sentence context. The grammatical cases of a Serbo-Croatian noun are formed by adding to the root form an inflectional morpheme, usually a suffix consisting of one syllable of the vowel or vowel-consonant type. Inflecting the noun may also involve deleting a vowel and palatalizing a consonant. At all events, in normal linguistic usage the grammatical cases formed are preceded by a preposition that serves (1) to specify which particular grammatical case is intended (when more than one grammatical case is represented by a given orthographic and phonological structure) and (2) to specify which particular meaning of the grammatical case is intended (when more than one meaning is associated with a given grammatical case). In other words, the relationship of a preposition to a grammatical case is one of complementation. In isolation, the grammatical 
information revealed by a particular case (with the exception of the nominative and vocative) is equivocal. This equivocality is reduced through a preposition that specifies the case and clarifies its role in the sentence, pointing to the particular meaning it is to assume. And it is reduced further by the overall context of the sentence.

Significantly, the preposition/inflected noun relation is more properly described as a grammatical or functional relation rather than as a semantic association. We would not, in short, expect prepositions and inflected nouns to be cross-referenced in the lexicon in the same manner that Forster (1976) conceives semantic relatives to be cross-referenced. Indeed, there is some reason to believe that for English the internal representation of function words (prepositions and the like) is not common with the internal representation of content words. Thus, phonemic dyslexics who are generally unable to read pseudowords are generally successful at reading words, with the curious exception of function words. Apparently, phonemic dyslexics relate to function words as if they were, like pseudowords, without representation in the lexicon and, therefore (given the inability to derive phonology rulefully from script), unreadable (Patterson \& Marcel, 1977). In a related observation, Bradley (1978) notes that whereas lexical decision on content words is faster the higher the frequency of the word, lexical decision on function words is independent of frequency of occurrence.

The preposition/inflected noun relationship is significant in another way. As noted, the inflected nouns of Serbo-Croatian are most usually preceded in normal spoken and written discourse by an appropriate preposition. A preposition, therefore, is quite legitimately a "sentence fragment," and if a facilitation of the lexicon by prepositional primes can be demonstrated, then it is reasonable to assume that in the more natural setting of sentence perception (as contrasted with word-list perception), parts of a sentence perceptually facilitate other parts. There is already good reason to believe that the preposition/inflected noun relation is significant in auditory sentence processing by reducing the reliance on preserving or attending to word order. In Serbo-Croatian, prepositions and inflected endings serve as local markers of a word's role and appear to contribute to the more rapid acquisition of some sentence processing strategies by young listeners of Serbo-Croatian as compared to young listeners of English (Ammon \& Slobin, 1979).

We chose to investigate the effect of appropriate, inappropriate, and nonsense prepositions on lexical decision to Serbo-Croatian nouns in three grammatical cases: the nominative singular, the locative singular, and the instrumental singular. The nominative singular form of the noun is thoroughly independent of prepositions; there is none by which it is prefaced. In contrast, the locative singular depends solely and fully on a preposition for the specification of both meaning and case. There are six meanings associated with the locative singular, and its written form is not unique, since other grammatical cases of the noun are spelled the same way (for example, the dative singular). For each of the six locative singular meanings, there is a preposition, and that preposition necessarily and sufficiently specifies the meaning. The sentence context is superfluous. With regard to the instrumental singular case, it is in one sense simpler than the locative singular case, namely, there are no other cases that share the same form. In another sense, however, the instrumental singular is more complex. It has 16 possible meanings (Ivic, Note 1) for which a meaning depends either on a preposition or on the sentence context. A preposition, therefore, is only occasionally necessary and sufficient to specify the meaning of a noun in the instrumental singular.

It is important to underscore that there is neither a simple visual relation nor a straightforward associative relation between prepositions and grammatical cases in Serbo-Croatian. A given preposition may go with more than one grammatical case. Moreover, the set of prepositions linked to one grammatical case is not visually distinct from the set of prepositions that is linked to another grammatical case. The letters comprising the different prepositions and the letters comprising the inflected endings that mark the different grammatical cases are not systematically related.

One would intuit from the foregoing discussion that in everyday sentence comprehension, an appropriate preposition would facilitate, and an inappropriate preposition might hinder, the grammatical and semantic evaluation of a noun in the locative singular form. And by comparison, the positive contribution of an appropriate preposition to the evaluation of a noun in the instru. mental singular form would be generally less marked, and the negative contribution of an inappropriate preposition would be negligible. Carrying this intuition over into the lexical decision task, we would expect (1) lexical decision to locative singular forms to be facilitated and inhibited by appropriate and inappropriate prepositional primes, respectively, (2) lexical decision to instrumental singular forms to be facilitated less and inhibited not at all by appropriate and inappropriate prepositional primes, respectively, and (3) lexical decision to nominative singular forms to be unaffected by prepositional primes of either kind.

\section{METHOD}

\section{Subjects}

Ninety-nine students from the Department of Psychology, University of Belgrade, received academic credit for participation in the experiment. A subject was assigned to one of nine subgroups, according to the subject's appearance at the laboratory. There were 11 subjects/subgroup.

\section{Materials}

Two types of slides were constructed. In one type, a string of Letraset lowercase Roman letters (Helvetia Light, 12 point) was arranged horizontally in the upper half of a $35-\mathrm{mm}$ slide, and in the other type, letters of the same kind were arranged 
horizontally in the lower half of a $35-\mathrm{mm}$ slide. Letter strings in the first type of slide were always prepositions (or pseudoword analogues) and letter strings in the second type of slide were always inflected nouns (or pseudoword analogues). Altogether, there were 120 "preposition" slides and 120 "inflected noun" slides, with each set evenly divided into words and pseudowords. The 60 inflected noun slides that were words consisted of three sets of 20 representing the nouns, respectively, in nominative singular, locative singular, and instrumental singular. The 20 nouns were selected from the middle frequency range of a corpus of 1 million Serbo-Croatian words (Kostic, Note 2). A different set of 20 nouns of the same frequency was used to generate the pseudowords. This was done by simply changing the first letter of the nouns in the nominative singular and locative singular and by changing either the first letter or the final one or two letters for the nouns in instrumental singular.

Across genders, the nominative singular form ends in either a vowel or a consonant, the locative singular always ends in a vowel, and the instrumental singular always ends in a consonant. Importantly, apart from the instrumental singular form and the occasional nominative singular form, the grammatical cases of Serbo-Croatian nouns end in a vowel. We wished to arrange matters so that both beginnings and endings of letter strings contributed to negative decisions. We also wished to do as little damage as possible to the root morphemes and to make the pseudoword versions of the nominative singular, locative singular, and instrumental singular cases of a given word form a coherent set. We could not substitute the vowel ending of a locative singular by another vowel ending, because that would always generate the same word in another grammatical case. We could substitute another consonant for the terminal consonant of a nominative singular, but that would render the overall set of derived pseudowords less coherent than we desired, because the nominative singular of nouns in the masculine is the root morpheme. We chose, therefore, to modify the endings of some of the nouns in instrumental singular. All things considered, that seemed to us the most prudent manipulation.

The preposition slides and the inflected noun slides were grouped into pairs such that (1) the inflected noun slides contained a word in one half of the pairs and a pseudoword in the other half and (2) the preposition slides contained a preposition specific to locative singular (one of "na," "po," "pri"), or a preposition specific to instrumental singular (one of "sa," "nad," "pred"), or a monosyllabic pseudoword (12 pseudowords were used: "uk," "af," "nu," "fe," "fo," "pug," "tir," "dri," "vak," "knid," "pler," and "tev"). In total, there were 1,080 different pairs of slides, of which a given subject saw 120 pairs.

\section{Design}

As remarked, each word and pseudoword appeared in three grammatical cases. The major constraint on the design of the experiment was that a given subject never encountered a particular word or pseudoword in any grammatical case more than once. This was achieved in the following manner.

of the 120 word and pseudoword stimuli, 12 stimuli (6 words and 6 pseudowords) were used for practice. The remaining 108 words and pseudowords were divided into three groups (A, B, and C), with 36 items in each group. Each of these three groups was further divided into three subgroups $(a, b$, and $c)$ of 12 items each (6 words and 6 pseudowords).

Ninety-nine subjects were divided into three groups $(1,2$, and 3) with 33 subjects in each group. Further division was undertaken by which each group of subjects was divided into three subgroups (I, II, and III) with 11 subjects each.

Note that there were six parameters in the design: three groups of words $(A, B, C)$ with three subgroups each $(a, b, c)$; three preposition types (locative specific, instrumental specific, and nonsense); three grammatical cases (nominative singular, locative singular, instrumental singular); and three groups of subjects $(1,2,3)$, each divided into three subgroups (I, II, III). In short, each subject in each subgroup of 11 subjects saw each grammatical case/preposition-type combination; but across the nine subgroups of 11 subjects, the nine grammatical cases/ preposition-type combinations were defined on different subsets of 12 nouns (i.c., 6 words and 6 pseudowords). Therefore, an individual subject, while seeing all grammatical case/prepositiontype combinations, never saw the same noun twice, but all subjects did see all 108 base stimuli. Put differently, each subject saw the same nouns as every other subject, but not necessarily in the same grammatical case and not necessarily preceded by the same preposition type.

\section{Procedure}

Two slides were presented on each trial. The subject's task was to decide as rapidly as possible whether the letter string contained in a slide was a word or a pseudoword. Each slide was exposed in one channel of a three-channel tachistoscope (Scientific Prototype, Model GB), illuminated at $10.3 \mathrm{~cd} / \mathrm{m}^{2}$. Both hands were used in responding to the stimuli. Both thumbs were placed on a telegraph-key button close to the subject, and both forefingers were placed on another telegraph-key button 2 in. farther away. The closer button was pressed for a "no" response (the string of letters was not a word), and the farther button was pressed for a "yes" response (the string of letters was a word).

Latency was measured from slide onset. The subject's response to the first slide terminated its presentation and initiated the second slide, unless his latency exceeded $1,300 \mathrm{msec}$, in which case the second slide was initiated automatically. The presentation of the second slide, like that of the first, was terminated by the keypress.

\section{RESULTS AND DISCUSSION}

A mean reaction time was computed for each subject by averaging over the nouns in each combination of grammatical case and preposition type. The means (based on individual subject means) for the nouns are given in Table 1. The entries in this table are based on 52 words rather than the original $54 ; 2$ words were aligned with the wrong prepositions and had to be discarded. The ordering of the latencies for the three inflected forms that is shown in Table 1 is identical to the ordering reported by Lukatela, Gligorijević, Kostić, and Turvey (1980): The nominative singular is responded to more quickly than the locative singular and instrumental singular, which, interestingly, are responded to at nearly the same speed even though their frequencies of occurrence differ markedly. (Refer to Lukatela et al., 1980 , for a discussion of the representation of SerboCroatian noun systems in the internal lexicon.) Table 2 gives the subjects' means for the pseudonouns.

Table 1

Acceptance Latencies for Nouns as a Function of Grammatical Case and Preceding Preposition

\begin{tabular}{lccc}
\hline & \multicolumn{3}{c}{ Grammatical Case } \\
\cline { 2 - 4 } Preposition Type & $\begin{array}{c}\text { Nomina- } \\
\text { tive }\end{array}$ & Locative & $\begin{array}{c}\text { Instru- } \\
\text { mental }\end{array}$ \\
\hline Pseudo & 639 & 708 & 696 \\
Locative Specific & 659 & 682 & 681 \\
Instrumental Specific & 658 & 722 & 665 \\
\hline
\end{tabular}


Table 2

Rejection Latencies for Nouns as a Function of Grammatical Case and Preceding Preposition

\begin{tabular}{lccc} 
& \multicolumn{3}{c}{ Grammatical Case } \\
\cline { 2 - 4 } \multicolumn{1}{c}{ Preposition Type } & $\begin{array}{c}\text { Nomina- } \\
\text { tive }\end{array}$ & Locative & $\begin{array}{c}\text { Instru- } \\
\text { mental }\end{array}$ \\
\hline Pseudo & 751 & 732 & $\mathbf{8 0 0}$ \\
Locative Specific & 728 & 745 & 788 \\
Instrumental Specific & 726 & 724 & $\mathbf{8 0 3}$ \\
\hline
\end{tabular}

An analysis of variance conducted on the noun and pseudonoun data, using subject variability as the error term, revealed a significant interaction of Word Lexicality (real, pseudo) by Preposition Type (locative, instrumental, nonsense) by Grammatical Case (nominative, locative, instrumental) $[\mathrm{F}(4,392)=10.81$, MSe $=$ $27.48, p<.001]$. This significant interaction encourages treating the noun data and the pseudonoun data separately. The pseudonoun data, represented in Table 2 , are considered first.

An analysis of variance on the pseudonouns, with subject variability as the error term, revealed that the case of the pseudonoun was significant $[F(2,196)=$ $102.21, \mathrm{MSe}=3,356, \mathrm{p}<.001]$, as was the interaction of Preposition Type by Grammatical Case $[F(4,392)=$ $4.09, \mathrm{MSe}=2,928, \mathrm{p}<.005$ ]. Using stimulus variability as the error term, the analysis of variance yielded only one significant effect, namely, that of grammatical case $[F(2,102)=40.89, \mathrm{MSe}=5,020, \mathrm{p}<.001]$. A significant interaction of Preposition by Case would suggest that grammatical agreement between the preposition and the case of the noun from which the pseudonoun was derived made it more difficult to reject the pseudonoun as a word. Recall that, for the majority of instances, the pseudonouns were generated from nouns by changing a single letter. The significant effect of case was due principally to the pseudonouns in the instrumental singular, which were responded to exceptionally slowly. This may have been due to the fact that instrumental singular pseudonouns were generated by changing the final letter or final pairs of letters of an instrumental singular noun. For the other two cases, the change that rendered a noun a pseudonoun was made on the initial letter.

An analysis of variance on the subjects' means for real words revealed that the case of the noun was significant $[F(2,196)=41.0, M S e=4,904, p<.001]$, as was the interaction of Case by Preposition $[F(4,392)=$ $14.27, \mathrm{MSe}=2,473, \mathrm{p}<.001]$. Preposition type missed significance $[F(2,196)=2.38, \mathrm{MSe}=2,434, p>.05]$. An analysis of variance using stimulus variability as the error term revealed that case was significant $[F(2,102)=$ 28.19, MSe $=3,872, p<.001]$, the interaction of Case by Preposition was also significant $[F(4,204)=1,066$, MSe $=2,735, p<.001]$, and the effect of preposition type was not significant $[\mathrm{F}(2,102)=1.51$, MSe $=3,297$, $\mathrm{p}>.05]$.
Focusing now on the specific predictions, it was supposed that of the three forms the locative singular should be most affected by appropriate and inappropriate prepositions, the instrumental singular should be affected considerably less so, and the nominative singular should not be affected at all. A one-way analysis of variance conducted on nominative singular forms with subjects' means revealed a significant effect of preceding prepositions $[\mathrm{F}(2,196)=5.93, \mathrm{MSe}=2,089, \mathrm{p}<.005]$. Inspection of Table 1 suggests that this effect reflects a contrast between prepositions and pseudoprepositions. A protected $t$ test (Cohen \& Cohen, 1975) confirmed that there was no difference between nominative singular forms preceded by locative-specific and instrumentalspecific prepositions. Protected t tests, however, showed that nominatives preceded by either of these prepositions were accepted more slowly than nominatives preceded by pseudoprepositions $[\mathrm{t}(98)=2.91, \mathrm{p}<.05]$. An analogous one-way analysis of variance conducted on instrumental singular forms also revealed a significant effect of prepositions $[\mathrm{F}(2,196)=9.00, \mathrm{MSe}=$ $2,584, p<.001]$. For this case, protected $t$ tests revealed that all contrasts were significant $[t(98)=2.20$, $\mathrm{p}<.05, \mathrm{t}(98)=2.07, \mathrm{p}<.05$, and $\mathrm{t}(98)=4.27, \mathrm{p}<.01$, for the locative-instrumental contrast, the locativepseudopreposition contrast, and the instrumentalpseudopreposition contrast, respectively]. Finally, a one-way analysis of variance conducted on locative singular forms with subjects' means was significant $[F(2,196)=15.05, \mathrm{MSe}=2,706, \mathrm{p}<.001]$. Protected $t$ tests revealed two significant contrasts: Locative nouns preceded by locative prepositions differed from locative nouns preceded by pseudoprepositions $[\mathrm{t}(98)=$ $3.63, p<.01]$, and locative nouns preceded by locative prepositions differed from locative nouns preceded by instrumental prepositions $[t(98)=5.38, p<.01]$.

An analogous one-way analysis of variance using the variability among stimuli as the error term failed to find significance for the nominative and instrumental cases. In contrast, a significant effect of prepositions was found for the locative singular case $[\mathrm{F}(2,102)=7.19$, $\mathrm{MSe}=3,602, \mathrm{p}<.001]$.

In summary, it can be argued that appropriate prepositions produced faster lexical decisions on subsequent nouns than did inappropriate prepositions. It cannot be argued, however, that inappropriate prepositions inhibited lexical decisions on subsequent nouns, partly because of uncertainty as to the appropriateness of the pseudopronoun baseline. This uncertainty is engendered by the observation that prepositions slowed lexical decisions on nominative singular forms relative to pseudoprepositions. The reason might be related to the way that Serbo-Croatian noun systems are organized (Lukatela et al., 1980), with a qualitative difference in the role of the nominative singular and oblique cases: Whereas a pseudopreposition may be unbiased, a preposition may direct processing to the oblique subset and away from the nominative singular. 
The present data provide evidence for a type of priming that is more appropriately termed grammatical rather than semantic. Insofar as priming effects similar to the kind reported here are dependent on the interval between prime and target (e.g., Tannenhaus, Leiman, \& Seidenberg, 1979), the use of only one interval in the present experiment curtails generalizing the present observation. A further curtailment follows from the fact that a lexical decision task was used rather than a naming task, which may be closer to reading. With these caveats in mind, the present observation of prepositions facilitating nouns can be added to other findings (e.g., Fischler \& Bloom, 1979; Kleiman, 1980) that suggest that lexical facilitation occurs among sentential components and that priming, therefore, may be a process that occurs in normal reading.

\section{REFERENCE NOTES}

1. Ivić, M. Case system in Serbo-Croatian language (in SerboCroation). Internal publication of the University of Novi Sad, 1964.

2. Kostić, Dj. Frequency of occurrence of words in SerboCroatian. Unpublished paper, Institute of Experimental Phonetics and Speech Pathology, Belgrade, Yugoslavia, 1965.

\section{REFERENCES}

Ammon, M. S., \& Slobin, D. I. A cross-linguistic study of the processing of causative sentences. Cognition, 1979, 7, 3-17.

Bradley, D. C. Computational distinctions of vocabulary type. Unpublished doctoral dissertation, Massachusetts Institute of Technology, 1978.

Blank, M. A., \& Foss, D. J. Semantic facilitation and lexical access during sentence processing. Memory \& Cognition, 1978, 6, 644-652.

Cohen, J., \& Cohen, P. Applied multiple regression/correlation analysis for the behavioral sciences. Hillsdale, N.J: Erlbaum, 1975.

Fischle r, I. Semantic facilitation without association in a lexical decision task. Memory \& Cognition, 1977, 5, 335-339.

Fischler, I., \& Bцoom, P. A. Automatic and attentional processes in the effects of sentence contexts on word recognition.
Journal of Verbal Learning and Verbal Behavior, 1979, 18, $1-20$.

Forster, K. I. Accessing the mental lexicon. In R. J. Wales \& E. Walker (Eds.), New approaches to language mechanisms. Amsterdam: North-Holland, 1976.

KLEIMAN, G. M. Sentence frame contexts and lexical decisions: Sentence acceptability and word-relatedness effects. Memory \& Cognition, 1980, 8, 336-344.

Lukatela, G., Gligorijević, B., Kostić, A., \& Turvey, M. T. Representation of inflected nouns in the internal lexicon. Memory \& Cognition, 1980, 8, 415-423.

Meyer, D. E., Schvaneveldt, R. W., \& Ruddy, M. G. Loci of contextual effects on visual word recognition. In P. Rabbitt \& S. Dornic (Eds.), Attention and performance V. New York: Academic Press, 1975.

Morton, J., \& Long, J. Effect of word transitional probability on phoneme identification. Journal of Verbal Learning and Verbal Behavior, 1976, 15, 43-51.

NeELY, J. H. Semantic priming and retrieval from lexical memory: Roles of inhibitionless spreading activation and limited-capacity attention. Journal of Experimental Psychology: General, 1977, 106, 226-254.

Patterson, K. E., \& Marcel, A. J. Aphasia, dyslexia and the phonological coding of written words. Quarterly Journal of Experimental Psychology, 1977, 29, 307-318.

Scarborough, D. L., Cortese, C., \& Scarborough, H. Frequency and repetition effects in lexical memory. Journal of Experimental Psychology: Human Perception and Performance, 1977, 3, 1-17.

Schube rth, R. F., \& Eimas, P. Effects of context on the classification of words and nonwords. Journal of Experimental Psychology: Human Perception and Performance, 1977, 3, 27-36.

Stanovich, K. E., \& West, R. F. The effect of sentence context on ongoing word recognition: Tests of a two-process theory. Journal of Experimental Psychology: Human Perception and Performance, 1981, 7, 658-672.

Tannenhaus, M. K., Leiman, J. M., \& Seidenberg, M. S. Evidence for multiple stages in the processing ambiguous words in syntactic contexts. Journal of Verbal Learning and Verbal Behavior, 1979, 18, 336-344.

UNDERWOOD, G. Contextual facilitation from attended and unattended messages. Journal of Verbal Learning and Verbal Behavior, 1977, 16, 99-106.

(Received for publication November 10, 1981; revision accepted September 15, 1982.) 